\title{
SOCIAL SITUATION, AGE AND GENDER ASSIGNMENT TO ENGLISH NOUNS: A STUDY OF SOCIOLOGY OF LANGUAGE
}

\author{
Judith Lee Conboy \\ Kansas State University
}

Mid-American Review of Sociology, 1978, Vol. 3, No. 1:17-38

A series of tests was developed for the purpose of determining the likelihood that individuals would assign gender to: 1) norms when observed and heard individually as a part of a list of words; 2) sets of two norms which reflect definite contrast sets; and 3) groups of three norms which imply the existence of a specific social situation in a particular social institution. Age of the respondent was a significant variable in the assignment of gender. The study was guided by the Whorfian Hypothesis, particularly the idea that grammatical characteristics of language facilitate or make more difficult various nonlinguistic behaviors. Two hundred and fifty-six (256) students were chosen and tested in selected grades of a southwest Missouri school system including a community college. Two fifth grade, two seventh grade, two eleventh grade and two college classes were utilized.

\section{INTRODUCTION}

The role of verbal and non-verbal communication in group life has long been recognized by sociologists as a necessary component of human social organization. The idea that language is what makes human beings human is emphasized by the symbolic interaction school. As Manford Kuhn (Braum, 1970:14) has said: "The whole epistemology of symbolic interaction, from Cooley to Cassirer, rests on the proposition that language is necessarily interposed between man and raw reality so that he can never confront it directly."

Joshua Fishman notes:

... language is not merely a means of interpersonal communication and influence. It is not merely a carrier of content whether latent 
or manifest. Language itself is content, a referent for loyalties and animosities, an indicator of social statuses and personal relationships, a marker of situations and topics as well as of societal goals and the large scale value-laden arenas of interaction that typify every speech community (Fishman, 1972:4).

The study of gender usage in language was a general interest among linguists and anthropologists of the late nineteenth century (Ibrahim, 1973:11) and early twentieth century, but has been neglected by both in recent years. In fact, Ibrahim (1973:14) asserts that our knowledge on the subject has advanced suprisingly little since Greco-Roman antiquity. Unlike other of the Indo-European languages, Standard English has not assigned gender to nouns since the disappearance of Old English (cf.Pyles, 1971), nor has it called for agreement between adjectives and nouns or other symbols of gender-like agreement between articles and nouns. Through the pronouns "he," "she," and "it," the masculine, feminine, and neuter genders appear, but their effects are far more meaningful than their short form and limited number imply. They, along with the personal names which indicate gender, establish the "sphere of influence" and designate the significance of the actor and the action.

The present study attempts to: 1) discover the extent to which gender assignment is a part of the language used by a sample of students; and 2) gain insight into how they construe their environment on the basis of language usage. If it can be shown that words which have few formal gender markings nevertheless convey cultural messages dividing the world up into genderized components, then there are some implications both for theory and for action. Within the field of sociology, the information would allow for greater understanding of social organization and social change. Practically, it might facilitate smoother transitions during times of social flux.

Beauvior (1953) has said that our language makes the male the basic reality and the female the "other." "[I] n anthropology classes we study Peking man and Neanderthal man; in other social science courses, economic man and political man" (Chafez, 1974:78). In sociology we learn about marginal man and feral man; we read the North-Hatt Occupation Index which scales only "men's" occupations. "Economists speak of manpower; organizations have chairmen ... We even pronounce couples, man (not husband) and wife (not woman)" (Chafez, 1974:78).

With a clearer understanding of how gender assignment through language divides the social group and the world, we might better anticipate areas of entrenched committment not only to social roles, but also to the language we use in talking or writing about those roles. With this kind of information, we might have expected to find reluctance in sharing leadership roles as well as hesitancy in renaming the positions (e.g., we could have anticipated reluctance in accepting women as leaders as well as hesitancy in renaming power positions from chairman to chair, or alternately chairman/chairwoman).

\section{THEORETHICAL BACKGROUND}

The Whorf-Sapir principle was expressed by Benjamin Whorf (Fishman, 1969:125) as follows: "The world is presented in a kaleidoscope flux of impressions which has to be organized... largely by the linguistic systems in our minds." Alternatively, Sapir (Bernstein, 1971:121) has said: "Language is a guide to 'social reality'... the real world is to a large extent unconsciously built upon the language habits of the group... the language habits of our community predispose certain choices of interpretation."

Essentially these theorists have a linguistic-relativity view of the relationship between language structure and social behavior. Language form and usage are considered "givens" with all social behavior being influenced by the predisposing linguistic fact. Other perspectives include a linguistic-reflection view which claims that social structure and behavior precede and language merely reflects them (Warfel, 1962), and a language-constraint perspective. "According to ... [the latter] view, the form of the social relation or, more generally, the social structure generates distinct linguistic forms or codes and these codes essentially transmit the culture and so constrain behavior" (Bernstein, 1971:122). Fishman (1972:171) suggests that the issue of "what 
caused what" be put aside for the more productive and fascinating study of "the ongoing and intertwined conversation and interaction. In these processes, language and societal behavior are equal partners rather than one being 'boss' and 'giving orders' to the other."

The current study was carried out within the theoretical framework established by level 4 of the Whorfian hypothesis. Specifically, an analysis was made of the relationship between gender assignment to nouns and the recognition of three (3) increasingly apparent social situations. Following Greenfield's methodology in the study of diglossia, domains (or social situations) were implied through situational-linguistic cues (Fishman, 1971:250-251). Recognition of the various domains (or social situations) provided the non-linguistic behavior response for the current investigation.

Four null hypotheses were formulated, as follows:

1. There will be no significant tendency to assign gender to nouns when they are heard and observed individually.

2. There will be no significant increasing tendency to assign gender to nouns when they appear in contrast sets.

3. There will be no significant increasing tendency to assign gender to nouns when they are made more situation specific by being grouped within domains.

4. There will be no significant correlation between assigning gender and increasing age of the respondents until the situation becomes more obvious through contrast sets and domains.

The .05 level was prescribed for all four hypotheses.

\section{METHODOLOGY}

A series of tests was developed for the purpose of determining the likelihood that individuals would assign gender to: 1 ) nouns when observed and heard individually as a part of a list of words; 2) sets of two nouns which reflect definite role relationships; and 3) groups of three nouns which imply the existence of a specific social situation in a particular social institution.
Two hundred and fifty-six (256) students were chosen and tested from the student population in selected grades of the Joplin Public School system and Missouri Southern State College. Two fifth grade classes, two seventh grade classes, two eleventh grade classes, and two college classes were utilized. The small size of the sample and its non-randomness make this an exploratory study.

\section{Instrument Construction}

In discussing gender from a non-grammatical perspective, Oakley (1972:158) states: “' 'Sex' is a biological term; 'gender' a psychological and cultural one... Needless to say, every society believes that its own definitions of gender correspond to the biological duality of sex." Oakley goes on to say that " $[s] \mathrm{ex}$ differences may be 'natural,' but gender differences have their source in culture, not nature" (1972:189). She then explains that much of the current confusion and debate over sex roles is the result of thinking and speaking of "sex differences" when the distinctions being made are really "gender differences." "Mostly the social situation defines gender (wife-woman, dentist-man, and so on)" (Oakley, 1972:161).

Since gender appears to be tied into the situation, and since communications, both verbal and non-verbal, provide the means for developing the social situation, two guideline questions were raised: Will nouns elicit gender responses? If so, will there be an increasing tendency to assign gender as the social situation becomes more apparent?

The methodological concern of this study was to develop an instrument which would be capable of measuring the extent to which English nouns and social . situations are linguistically categorized by gender. The means for identifying social situations on the testing instruments were provided through the concepts of domains and contrast sets. Domains were treated as the sociolinguistic counterpart to the concept of social institutions, while contrast sets substituted to a certain extent for the sociological construct of role-relationship.

Domains provide more abstract representations than specific role-relationships within a bounded time and place setting. They 
represent clusters of lingual settings and interlocutors in networks of interaction. Greenfield's study of diglossia in a Puerto Rican speech community proved that domains could be analyzed through situational-linguistic cues (Fishman, 1971:250-251).

While the concept of role-relationship is a very instructive one, it was too limited for the present study. Social roles are most often associated with one sex or the other. An attempt was made in this study to determine if the social situation was associated with masculine or feminine characteristics, rather than just role relationships within those situations. The verbal cues which were used in developing the situation were nouns representing persons, places, things and qualities; therefore, role relationships were not the entire, or even the primary, source for implying social situations. For example, in the second test administered to the subjects, words which were seen in pairs included: mother/father, boss/workplace, judge/law, moon/sun, and peace/honor.

The concept of contrast sets, borrowed from ethnoscience, proved most useful in the development of the instrument. Contrast sets could include all of the elements in the social situation: roles, time settings, places, and facilities. According to Sturtevant, the concept of contrast sets

$\ldots$ is relative to the environment within which it occurs. Thus the mutual exclusion in English between 'ant' and 'ship' (Conklin, 1962:127) or between 'hamburger' and 'rainbow' (Frake, 1962:79) is not contrast in this sense, because the environment which they share is not culturally relevant. As Frake (1962:79) puts it, 'In writing rules for classifying hamburgers I must say something about hot dogs, whereas I can ignore rainbows. Two categories contrast only when the differcnce between them-is significant for defining their use' (Sturtevant, 1974:162).

From a sociological perspective, contrast sets are like role-relationships, complementary relationships. The social situation provides the setting for social roles and the framework for contrast sets. From a sociological perspective, domains are like social institutions-large-scale aggregative regularities of behavior related to widespread sociocultural norms and expectations, and serving recognized functions (Fishman, 1972:43). From these concepts the testing instruments were devised.

Ninety nouns were chosen for use on all three tests. They were familiar words recognizable to people from the fifth grade through college level classes, and they had enough variety to be utilized in a list, in contrast sets, and in domains without adding new words. This was done so that new factors would not enter into the testing process. ${ }^{2}$

The purpose of the first test was to determine whether masculine and feminine gender would be assigned more often than by chance to English nouns when they were heard and observed individually. If this were the case, then the first null hypothesis could be rejected. The purpose of the second test was to determine whether there would be an increasing tendency to assign gender to words when they were paired to imply social situations. If this were the case, then the second null hypothesis could be rejected. The primary purpose of the third test was to determine whether there would be an increasing tendency to assign gender to words when they were grouped to suggest familiar sociolinguistic domains. If this point were supported, the third null hypothesis could be rejected.

All three of the tests served to determine whether age would be a significant factor in recognizing the gender implications of English nouns, and whether increasing situation specificity would affect gender assignments. It was expected that a tendency to assign gender to words in lists would be apparent in the older groups (college/high school) but not in the younger groups (junior high/grade school). As the social situation became more apparent in the second and third tests, it was expected that the difference by, age groups would largely disappear, and that the younger groups would assign gender as often as the older groups. If this were the case, then the fourth null hypothesis could be rejected.

\section{Validity and Reliability}

The primary validity check was a comparison of the percentage of responses to a fictitious word, waissel (pronounced way-sell), with the rest of the words which were real. In using a 
fictitious word, it was assumed that if a word were recognized, then there would be a tendency for it to be genderized; if the word were not recognized (as with the fictitious word), then there would be a tendency for it to be neuterized. This occurred in the present study, as Table I indicates.

Attention is directed particularly to the responses in the neuter categories for both the fictitious word and the real words. The null hypothesis for the test of validity was: There will be no significant increase in the tendency to assign neuter to a fictitious word. It was assumed that if the respondents were honestly trying to assign gender, a large number would be unable to place waissel in either the masculine or feminine categories because they would not know the word. It was expected, therefore, that a significant difference would occur between the number of neuter assignments on the real words and those on the fictitious word. This proved to be the case for on the first test $76.27 \%$ of the responses for the word waissel were in the neuter category, while only $47.96 \%$ of the responses for the real words were marked neuter. On the second test the word waissel received $80.34 \%$ neuter responses, while the real words were marked neuter only $43.46 \%$ of the time.

In considering reliability, a split-half analysis was done on two classes (7th grade and 11th grade) drawn and separated at random. After devising an ordinal score for the gender categories, a simple analysis of variance statistical test was carried out. The results clearly indicated that all three of the tests were getting similar responses from each half of the junior high group and each half of the high school group.

The randomness of the sample is often in question when the population is a school system. The researcher must often work with those individuals made available through the administrative. personnel and cooperative faculty members (cf. Mueller, Schuessler, and Costner, 1970:348-362). This was the case for the present study. Therefore, any generalizations which might come out of the present study must be limited to the tested sample because an availability sampling was conducted to obtain subjects.
In Figure 1, the Whorfian Hypothesis is presented graphically ${ }^{1}$

\begin{tabular}{lcc}
\hline & \multicolumn{2}{c}{ Data of (Cognitive) Behavior } \\
\hline $\begin{array}{l}\text { Data of Language } \\
\text { Characteristics }\end{array}$ & $\begin{array}{c}\text { Language data } \\
\text { ("cultural themes") }\end{array}$ & $\begin{array}{c}\text { Nonlinguistic } \\
\text { data }\end{array}$ \\
\hline $\begin{array}{l}\text { Lexical or "semantic" } \\
\text { characteristics }\end{array}$ & Level 1 & Level 2 \\
\hline $\begin{array}{l}\text { Grammatical } \\
\text { characteristics }\end{array}$ & Level 3 & Level 4 \\
\hline
\end{tabular}

Figure 1. Schematic Systematization of the Whorfian Hypothesis (Fishman, 1972:160)

TABLE I

TEST FOR CONSTRUCT VALIDITY: COMPARISON OF GENDER ASSIGNMENTS FOR A FICTITIOUS WORD,

WAISSEL, AND REAL WORDS ON TWO TESTS WHICH EXAMINE INCREASING SITUATION SPECIFICITY

\begin{tabular}{|c|c|c|c|c|c|c|}
\hline \multirow[t]{2}{*}{$\begin{array}{l}\text { Situation } \\
\text { Specificity }\end{array}$} & \multicolumn{3}{|c|}{ Waissel } & \multicolumn{3}{|c|}{ Real Words } \\
\hline & Masculine & Feminine & Neuter & Masculine & Feminine & Neuter \\
\hline $\begin{array}{l}\text { Noun List } \\
\text { (Test One) }\end{array}$ & $\begin{array}{r}29 \\
12.28 \%\end{array}$ & $\begin{array}{c}27 \\
11.44 \%\end{array}$ & $\begin{array}{c}180 \\
76.27 \%\end{array}$ & $\begin{array}{c}6,918 \\
32.90 \%\end{array}$ & $\begin{array}{c}4,021 \\
19.12 \%\end{array}$ & $\begin{array}{l}10,085 \\
47.96 \%\end{array}$ \\
\hline $\begin{array}{l}\text { Contrast } \\
\text { Sets } \\
\text { (Test One) }\end{array}$ & $\begin{array}{r}26 \\
11.11 \% \\
\end{array}$ & $\begin{array}{c}20 \\
8.54 \% \\
\end{array}$ & $\begin{array}{c}188 \\
80.34 \% \\
\end{array}$ & $\begin{array}{c}6,236 \\
35.39 \% \\
\end{array}$ & $\begin{array}{l}3,777 \\
21.43 \% \\
\end{array}$ & $\begin{array}{r}7,605 \\
43.36 \% \\
\end{array}$ \\
\hline
\end{tabular}




\section{FINDINGS}

In the present study, chi square tests of significance and independence were expressed in contingency tables with the independent variables appearing down the left side of the tables and the dependent variables appearing across the top. In each of the tables, there were three figures: first, the number of responses actually obtained when the test was administered; second, the statistically expected number of responses determined by the chi square equation; and third, the cell value. As a rule, the highest and lowest cell values have been analyzed first because they provide the key to explaining variations where they exist.

Table II compares the tendency of all respondents to assign gender on the three tests with the statistically expected responses.

When nouns were seen and heard independent of the social situation (first test), they were significantly under-assigned feminine gender (33.99) but were assigned masculine gender an expected number of times. (.0013). Neuter assignments were made more often then statistically expected (15.516). Masculine gender was over-assigned (31.10), and neuter gender was significantly under-represented (29.89), when nouns were placed in the social situation (second test). The number of feminine responses resulted in the statistically expected number. In the third test, domains, feminine gender assignments were over-represented (18.427), masculine assignments were under-represented (21.003), and neuter assignments were at the expected frequency (.936).

A general summary of the table indicates that: 1) Nouns in lists were assigned masculine or neuter gender more often than feminine gender. 2) Words obviously representing social situation (contrast sets) were most likely to be assigned masculine gender, less likely to be assigned feminine gender, and least likely to be neuterized. 3) Domains called forth feminine gender assignments more often than any other situation. Masculine and feminine gender tended to balance the neuter designations in the raw data. ${ }^{3}$

The information in Table II represents a compilation of all age levels for each of the tests. When each grade level is analyzed separately, there are some distinctive breaking points. Table III presents the results of the first test by subject's grade level.
TABLE II

COMPARISON OF TENDENCY FOR ALL RESPONDENTS TO ASSIGN GENDER ON THREE TESTS OF INCREASING SITUATION SPECIFICITY

\begin{tabular}{lccc}
\hline \multicolumn{1}{c}{ Test } & Masculine & Feminine & Neuter \\
\hline Noun list & 6,947 & 4,048 & 10,265 \\
(first test) & $(6,950)$ & $(4,436)$ & $(9,873)$ \\
& .001 & 33.99 & 15.51 \\
\cline { 2 - 4 } Contrast sets & 6,262 & 3,797 & 7,793 \\
(second test) & $(5,835)$ & $(3,725)$ & $(8,290)$ \\
& 31.10 & 1.38 & 29.89 \\
Domains & 8,094 & 5,753 & 12,206 \\
(third test) & $(8,516)$ & $(5,436)$ & $(12,096)$ \\
& 21.003 & 18.42 & .93 \\
\hline
\end{tabular}

Chi square $=152.25,4 \mathrm{df}$, sig. .001

TABLE III

COMPARISON OF ASSIGNMENT OF GENDER ON TEST ONE (NOUN LIST) BY GRADE LEVEL

\begin{tabular}{lccc}
\hline Grade Level & Masculine & Feminine & Neuter \\
\hline \multirow{3}{*}{ College } & 1,312 & 787 & 3,593 \\
& $(1,859)$ & $(1,083)$ & $(2,748)$ \\
& 161.43 & 81.27 & 259.63 \\
\hline \multirow{3}{*}{ High School } & 1,638 & 939 & 2,724 \\
& $(1,732)$ & $(1,009)$ & $(2,559)$ \\
& 5.12 & 4.90 & 208.77 \\
Jr. High & 1,482 & 739 & 1,672 \\
& $(1,272)$ & $(741)$ & $(1,879)$ \\
& 34.63 & .006 & 22.94 \\
\hline \multirow{3}{*}{ Grade School } & 2,515 & 1,583 & 2,276 \\
& $(2,082)$ & $(1,213)$ & $(3,077)$ \\
\hline \hline
\end{tabular}

Chi square $=991.38,6 \mathrm{df}$, sig. .001 
A distinctive breaking point occurred between junior high and high school, with fifth and seventh graders assigning masculine or feminine gender to words and eleventh and college level students neuterizing the same words. This age polarization became more consistent as the social situation was. made more apparent through contrast sets (test two) and domains (test three).

On the second test,comprised of contrast sets (see Table IV), the largest cell values again appeared in the neuter column and in the college and grade schools rows respectively. College students over-assigned neuter gender to nouns in contrast -sets and under-assigned masculine and feminine gender, while grade school students did just the opposite.

The third test, which placed the nouns in situation specific domains (see Table V), produced the following results: College students neuterized the nouns, while grade school students clearly under-represented the neuter category and over-assigned masculine and feminine gender. The break appeared for the third time between junior high and high school. There was a consistent pattern, and an age polarity in assigning gender was strongly suggested.

As the social situation became more specific from test one through test three, the subjects moved solidly in the direction initially established. The tendency to assign masculine gender was an interesting result. Even when the feminine responses were more than the chi square statistical expectations, the masculine assignments outnumbered the feminine. For example, among the responses by the grade school sample, which had a strong tendency to assign both masculine and feminine genders, the masculine tendency was obvious. Even though the trend was toward neuter -categorizations among the college level students, the masculine tendency was apparent when gender was assigned.

HYPOTHESIS ONE: There will be no significant tendency to assign gender to nouns when they are heard and observed individually.

There was a significant under-representation of the neuter category and over-assignment of. gender to nouns on word lists by the junior high and elementary school sample. This called for the rejection of the first null hypothesis. However, that was not the
TABLE IV

COMPARISON OF ASSIGNMENT OF GENDER ON TEST TWO (CONTRAST SETS) BY GRADE LEVEI.

\begin{tabular}{lccc}
\hline \hline Grade Level & Masculine & Feminine & Neuter \\
\hline \multirow{3}{*}{ College } & 1,144 & 715 & 2,899 \\
& $(1,668)$ & $(1,011)$ & $(2,077)$ \\
& 165.13 & 87.15 & 3.25 .29 \\
\hline \multirow{3}{*}{ High School } & 1,417 & 840 & 2,172 \\
& $(1,553)$ & $(942)$ & $(1,933)$ \\
& 12.005 & 11.04 & 29.44 \\
\hline \multirow{3}{*}{ Junior High } & 1,316 & 689 & 1,208 \\
& $(1,127)$ & $(683)$ & $(1,402)$ \\
& 31.68 & .04 & 26.99 \\
\hline \multirow{3}{*}{ Grade School } & 2,385 & 1,553 & 1,514 \\
& $(1,912)$ & $(1,159)$ & $(2,379)$ \\
& 116.78 & 133.46 & 315.09 \\
\hline
\end{tabular}

Chi square $=1254.14,6 \mathrm{df}$, sig. .001

TABLE V

COMPARISON OF ASSIGNMENT OF GENDER

ON TEST THREE (DOMAINS) BY GRADE LEVEL

\begin{tabular}{lccc}
\hline Grade Level & Masculine & Feminine & Neuter \\
\hline \multirow{3}{*}{ College } & 1,462 & 1,129 & 4,494 \\
& $(2,201)$ & $(1,564)$ & $(3,319)$ \\
& 248.19 & 121.22 & 415.66 \\
\hline \multirow{3}{*}{ High School } & 1,699 & 1,249 & 3,433 \\
& $(1,985)$ & $(1,411)$ & $(2,994)$ \\
& 41.34 & 18.65 & 67.26 \\
\hline \multirow{3}{*}{ Junior High } & 1,760 & 1,075 & 1,920 \\
& $(1,477)$ & $(1,049)$ & $(2,227)$ \\
& 54.11 & .59 & 42.51 \\
\hline \multirow{3}{*}{ Grade School } & 3,173 & 2,300 & 2,349 \\
& $(2,430)$ & $(1,727)$ & $(3,664)$ \\
& 227.11 & 189.92 & 472.33 \\
\hline
\end{tabular}

Chi square $=1898.95,6 \mathrm{df}$, sig. .001 
case with the college/high school sample, and their responses indicated that the first null hypothesis should be accepted. The conclusion was the difference in response by grade level made it necessary to accept the first null hypothesis with reservations.

HYPOTHESIS TWO: There will be no significant tendency to assign gender to nouns when they appear in contrasts sets.

When all of the respondents' scores were analyzed together, they showed a tendency to assign gender to contrasts sets However, when their scores were analyzed by grade level, the grade school/junior high students showed the tendency but the college/high school subjects did not. The second null hypothesis was accepted with reservations.

HYPOTHESIS THREE: There will be no significant tendency to assign gender to nouns when they are made more situation specific by being grouped within domains.

The third null hypothesis was supported with reservations. The junior high/grade school sample showed an increasing tendency to assign masculine or feminine gender by domains, while the college/high school sample showed an increasing tendency to assign neuter characteristics to words when they appear in domains.

HYPOTHESIS FOUR: There will be no significant correlation between assigning gender and increasing age of the respondents until the situation becomes obvious through contrasts sets and domains.

It had been anticipated that the older students would assign gender, and do so with increasing frequency, when the socia situation became more obvious through contrast sets and domains. It had also been anticipated that the younger students would not assign gender as frequently until the situation became more obvious through contrasts sets and domains. What happened in fact was that the junior high/grade school group and the older college group both became more likely to assign neuter to the words as the social situation became apparent. The last null hypothesis was accepted with reservations.

\section{SUMMARY OF THE FINDINGS AND CONCLUSIONS}

The three tests designed to determine the likelihood of assigning gender with increasing situation specificity resulted in partial success. On the first test, which presented nouns in a list, there was a decided separation in the responses of the grade school/junior high and high school/college level subjects. The younger group showed a definite tendency to genderize the nouns while the older group demonstrated the opposite tendency. The difference between the age extremes, grade school and college level, was pointed. There also was a difference between the middle range age groups, junior high and high school, but it was not as distinctive.

With each test, the tendency which was established in the responses to the nouns heard individually became stronger. Younger respondents clearly moved in the direction of assigning gender to words when they came in pairs or in groups of three. Older respondents definitely moved away from the possibility of assigning gender as the social situation became more apparent. When controlled for age, the data showed quite clearly that gender assignments were affected by the social situation.

It was particularly interesting that when gender was assigned, it was more often masculine than feminine. Even when feminine gender was assigned more frequently than was statistically expected, the raw data showed that masculine was always selected more often than feminine. The general tendency was to assign masculine or neuter to words.

Why was there such a definite and continuing separation in the tendency to assign gender between grade school/junior high and high school/college students? Two speculative explanations are offered.

First, by the time a student reaches the high school/college level, they have learned the formal rules of English grammar and are able to apply them to words without being distracted by the social setting. There was some evidence for this conclusion. Students taking a senior level college course in the History of the English Language were pretested, and a summary of the percent of their responses by masculine, feminine and neuter categories 
appears in Table VI. Attention is directed to the similiarity between the advanced college English students' responses and the total responses to the fictitious word, waissel, which also appears on Table VI.

The advanced college English students responded to real words in much the same way that other subjects responded to the fictitious word. Moreover, there was a significant difference between the responses of advanced college English students and those of all other students. The explanation offered is that these college seniors studying English grammar are probably more familiar with the formal rules of grammar, and are more likely to apply them to a test asking for gender assignments. This explanation could generalize to the older respondents on the current study who would perhaps be more likely to know and be able to apply formal rules of grammar. The younger students, perhaps being less familiar with the formal rules, responded from an experiential-attitudinal set.

A second explanation for the distinctive separation in gender assignment-tendencies between grade school/junior high and high school/college students might be related to attitudes which are perceived to be appropriate or inappropriate. Perhaps, the older student has begun to question the appropriateness of automatically assigning gender to social roles and social situations, and this was reflected in the tendency to move away from masculine/feminine designations and toward neuter categorizations as the social situation became more apparent.

The speculative conclusions which could be drawn from these findings are: As younger students (grade school/junior high) learn the formal rules of grammar dealing with gender, they rely on their experiences, perceive gender usage in the environment, and utilize gender as a conceptual category. As the older students (high school/college) become more familiar with the formal rules of gender usage, they also become more aware of social change as it relates to the role of women. Even though they might not be given much formal instruction on the topic, it cannot be avoided in the media, political campaigns, sporting events, or even in jokes, to name only a few areas. They must then "unlearn" the gender assignments of their earlier experiences in the lower grades for the
TABLE VI

COMPARISON OF ADVANCED COLLEGE ENGLISH STUDENTS GENDER ASSIGNMENTS FOR REAL WORDS ON THREE TESTS AND GENDER ASSIGNMENTS BY ALL RESPONDENTS TO WAISSEL A FICTITIOUS WORD, ON TWO TESTS

\begin{tabular}{lllllll}
\hline & \multicolumn{3}{c}{ College English Students } & \multicolumn{3}{c}{ All Respondents } \\
Test & Masculine & Feminine & Neuter & Masculine & Feminine & Neuter \\
\hline $\begin{array}{l}\text { Noun list } \\
\text { (test one) }\end{array}$ & $12.38 \%$ & $10.63 \%$ & $76.98 \%$ & $12.28 \%$ & $11.44 \%$ & $76.2 .7 \%$ \\
$\begin{array}{l}\text { Contrast sets } \\
\text { (test two) }\end{array}$ & $10.56 \%$ & $10.75 \%$ & $78.67 \%$ & $11.11 \%$ & $8.54 \%$ & $80.34 \%$ \\
$\begin{array}{l}\text { Domains } \\
\text { (test three) }\end{array}$ & $9.17 \%$ & $13.50 \%$ & $77.51 \%$ & - & - & - \\
\hline
\end{tabular}


more appropriate egalitarian conception of the social situation occasioned by the forces of social change.

Having observed that certain age groups are likely to assign gender to English nouns, the results indicated that the social situation affected gender assignments. The more obvious the situation, the more likely gender was assigned (or not assigned). If the language system and the social system are mutually interrelated, then gender assignments must also affect the construction of the social situation. To initiate speculations on the issue, contrast sets rather than role relationships were used to convey the social situation in the tests instruments. It was argued that role relationships imply persons, which is not necessarily the case with contrast sets. Role relationships implying persons of one or the other sex in inter-action with another person would aid in gender assignment because of the implied sex of the participants. The social situation would then construct the gender connotations. On the other hand, contrast sets could include not only role players, but also persons, places, things or qualities. If words other than role players were assigned gender, it was assumed that the gender conceptualization for the word helped in constructing the meaning of the social system. This occurred especially in younger subjects. Language interacts with situation, and the social situation interacts with language to create meaning.

\section{NOTES}

1. Fishman (1972:160-161) describes the Whorfian hypothesis in the following manner:

Level 1 of the Whorfian ("linguistic relativity") hypothesis predicts that speakers of languages that make certain lexical distinctions are enabled thereby to talk about certain matters (for example, different kinds of snow among speakers of Eskimo and different kinds of horses among speakers of Arabic) that cannot as easily be discussed by speakers of languages that do not make these lexical distinction. Similarly, Level 3 of the Whorfian hypothesis predicts that speakers of languages that possess grammatical features (absence of tense in the verbal system, as in Hopi, or whether adjectives normally precede or follow the noun, as in English vs. French) predispose these speakers to certain cultural styles or emphases (timelessness; inductiveness vs. deductiveness). These two levels of the Whorfian hypothesis have often been criticized for the anecdotal nature as well as for their circularity in that they utilized verbal evidence for both their independent (causal) and dependent (consequential) variables.

Level 2 of the Whorfian hypothesis predicts that the availability of certain lexical items or distinctions enables the speakers of these languages to remember, perceive, or learn certain nonlinguistic tasks more rapidly or completely than can the speakers of languages that lack these particular lexical items or distinctions. This level of the Whorfian hypothesis has been demonstrated several times-most recently and forcefully in connection with the differing color terminologies of English and Zuni-but it is difficult to argue that the absence of lexical items or distinctions in a particular language is more a cause of behavioral differences than reflection of the differing sociocultural concerns or norms of its speakers. As soon as speakers of Zuni become interested in orange (color), they devise a term for it. Language relativity should be more stable and less manipulable than that! Level 4 of the Whorfian hypothesis is the most demanding of all. It predicts that grammatical characteristics of languages facilitate or render more difficult various nonlinguistic behaviors on the part of their speakers. This level has yet to be successfully demonstrated via experimental studies of cognitive behavior.

2. A list of the nouns and their order of presentation on all three tests is available on request.

The following definition of terms was utilized:

1. NOUNS: Nouns are English words representing persons, places, things, and qualities. Eighty-nine selected nouns and one fictitious word were utilized in this presentation. 
2. GENDER: Gender characteristically includes masculine, feminine, and neuter in Indo-European languages (Pyles, 1971:126). When neuter exists along with masculine and feminine, it is considered opposed to masculine/feminine (Greenberg in Ibrahim, 1974:37). Masculine and feminine were considered gender assignments in the current investigation.

3. MASCULINE: Masculine was considered to be synonomous with strength, aggressiveness, goal-setting, manliness.

4. FEMININE: Feminine was considered to be synonomous with loving, helpful, passive, womanly.

5. NEUTER: Neuter was considered to be neither masculine nor feminine.

3. The original intention was to reject the null hypotheses if the .05 level of significance was reached. In the preceeding analysis the .001 was met, but as later discussion indicates, the conclusion was not a rejection of the null hypotheses.

\section{REFERENCES}

Beauvoir, $\mathrm{S}$.

1953 The Second Sex. New York: Knopf.

Berstein, B.

1971 Class, Codes and Control. London: Routledge and Kegan Paul.

Blom, J. and J. Gumprez

1972 "Social Meaning in Linguistic Structures: Code-Switching in Norway." In J. Gumprez and D. Hymes (eds.), Directions in Sociolinguistics: The Ethnography of Communication. New York: Holt, Rinehart and Winston, Inc.

Braun, E.

1970 "Some Perspectives on Non-Verbal Communication," Kansas Journal of Sociology 6(1-2):12-20.

Chafetz, J.

1974 Masculine/Feminine or Human: An Overview of the Sociology of Sex Roles. Itasca, Ill.: F.E. Peacock.
Chomsky, $\mathrm{N}$.

1972 Language and Mind. New York: Harcourt, Brace, Jovanovich.

Fishman, J.

1969 "A Systematization of the Whorfian Hypothesis." In A. Lindesmith and A. Strauss (eds.), Readings in Social Psychology. New York: Holt, Rinehart and Winston.

1971 Advances in the Sociology of Language. Paris: Mouton.

1972 The Sociology of Language: An Interdisciplinary Social Science Approach to Language in Society. Rowley, Mass.: Newbury House.

Grimshaw, A.

1966 "Directions for Research in Sociolinguistics: Suggestions of a Nonlinguist Sociologist." Sociological Inquiry 36:319-332.

1971 "Sociolinguistics." In J. Fishman (ed.), Advances in the Sociology of Language. Paris: Mouton.

Gumprez, J. and D. Hymes

1972 Directions in Sociolinguistics. New York: Holt, Rinehart, and Winston.

Humes, D.

1964 Language in Culture and Society: $A$ Reader in Linguistics and Anthropology. New York: Harper and Row, Publishers.

1967 "Models of the Interaction of Language and Social Setting." Journal of Social Issues 23:8-28.

Ibrahim, $M$.

1973 Grammatical Gender: Its Origin and Development. Paris Mouton.

Johnson, W.

1968 "The World of Not-Words." In P. Gleeson and N. Wakefield (eds.), Language and Culture: A Reader. Columbus, Ohio: Charles E. Merrill. 
Mueller, J., Schuessler and Costner

1970 Statistical Reasoning in Sociology. Boston: Houghton Mifflin Company.

Oakley, A.

1972 Sex, Gender, and Society. New York: Harper Colophon Books.

Pyles, $\mathrm{T}$.

1971 The Origins and Development of the English Language. New York: Harcourt, Brace, Jovanovich.

Sapir, E.

1949 Language: An Introduction to the Study of Speech. New York: Harcourt, Brace and World.

1968 "Language Defined." In P. Gleeson and N. Wakefield (eds.) Language and Culture: A Reader. Columbus, Ohio: Charles E. Merrill.

Sturtevant, W.

1974 "Studies in Ethnoscience." In B. Blount (ed.), Language Culture and Society. Cambridge, Mass.: Winthrop.

Warfel, $\mathrm{H}$.

1962 A Science of Human Behavior. Cleveland, Ohio: Howard Allen.

Whorf, B.

1956 Language, Thought and Reality: Selected Writings of Benjamin Lee Whorf. J. Carroll (ed.). Cambridge, Mass.: The M.I.T. Press.
MYRDAL'S AND SMELSER'S THEORIES OF SOCIAL CHANGE: AN EXPLICATION AND APPLICATION ${ }^{1}$

Ray Mosely

Eastern Illinois University

Mid-American Review of Sociology, 1978, Vol. 3, No. 1:39-61

This essay defines the concepts of modernization, development and progress, and identifies other concepts used in explaining social change at various levels of abstraction. Three theoretical perspectives are described, two of which, Smelser's value-added determinants of collective behavior and Myrdal's accumulative causation concept, are combined for use in analysis of case studies. These cases center around developing countries and regions, covering a variety of failure and success combinations with respect to directed change. The conclusions suggest that: 1) change will always occur; 2) accumulative or circular causation is a useful explanatory concept; and 3) systems have a structure such that elements of functional theories can be used to analyze and direct changes, and where such changes have failed in the past, it is usually due to a lack of this type of analysis.

The subject of social change has been intriguing to many social scientists. Gunnar Myrdal looked at social change from an economist's viewpoint as early as 1944 in his book An American Dilemma, a study of black Americans. Theorists have long sought to explain social change, social movements, collective behavior and other patterns of social interaction. According to Cameron:

Men apparently become most concerned with problems of social control and social change precisely at those times when ... the patterns of behavior are changing. Plato lived in the midst of political chaos. Hobbes, Locke, and Rousseau all witnessed political upheaval. Since the culture of any modern society seems likely to change, we might profitably study some of the processes by which changes occur ... (Cameron, 1966:3). 